\title{
Accelerated Real-Time Simulations for Testing a Reactive Power Flow Controller in Long-Term Case Studies
}

\author{
Katja H. Sirviö ${ }^{D},{ }^{1}$ Mike Mekkanen, ${ }^{1}$ Kimmo Kauhaniemi, ${ }^{1}$ Hannu Laaksonen, ${ }^{1}$ Ari Salo, ${ }^{2}$ \\ Felipe Castro, ${ }^{3}$ and Davood Babazadeh ${ }^{3}$ \\ ${ }^{1}$ School of Technology and Innovations, University of Vaasa, Vaasa 65200, Finland \\ ${ }^{2}$ Vaasan Sähköverkko, Vaasa 65100, Finland \\ ${ }^{3}$ Energy Division, OFFIS e.V., Oldenburg 26121, Germany
}

Correspondence should be addressed to Katja H. Sirviö; katja.sirvio@univaasa.fi

Received 14 February 2020; Accepted 13 May 2020; Published 5 June 2020

Academic Editor: Yang Li

Copyright $(92020$ Katja H. Sirviö et al. This is an open access article distributed under the Creative Commons Attribution License, which permits unrestricted use, distribution, and reproduction in any medium, provided the original work is properly cited.

This paper presents the development of an accelerated real-time cosimulation and testing platform, especially for long-term simulations of power systems. The platform is planned to be utilized in the development and testing of active network management functions for microgrids and smart grids. Long-term simulations are needed in order to study, for example, the potential weekly, monthly, or yearly usage of distribution-network-connected distributed energy resources for different technical flexibility services. In order to test new algorithms in long-term study cases, real-time simulations or hardware-in-the-loop tests should be accelerated. This paper analyzes the possibilities and challenges of accelerated long-term simulations in studying the potential use of a large-scale wind turbine for reactive power flow control between distribution system operator (DSO) and transmission system operator (TSO) networks. To this end, the reactive power flow control is studied for different voltage levels (HV and MV) in the Sundom Smart Grid in Vaasa, Finland. The control of reactive power flow between HV and MV networks is realized with a reactive power window control algorithm for a 3.6 MW MV-network-connected wind turbine with a full-scale power converter. The behaviour of the reactive power controller during long-term simulations is studied by offline and real-time simulations. Moreover, the real-time simulations are performed with both software-in-the-loop and controller-hardware-in-the-loop.

\section{Introduction}

Utilization of the distribution-network-connected distributed energy resources (DER), that is, flexibilities, is becoming increasingly important for improving local and system-wide grid resiliency and for providing the technical flexibility services needed by DSOs and TSOs. Flexibilities consist of active $(P)$ and reactive $(Q)$ power control of flexible resources, such as controllable distributed generation (DG) units, energy storages (ESs), controllable loads, and electric vehicles (EVs), which are connected in DSO grids. The flexibility services from DER for DSOs and TSOs can, for example, be realized as part of active network management (ANM) functions for grid-connected microgrids.

Currently, the standards for microgrids, especially IEEE and IEC, for control and management are under development, and only a few standards for microgrids have been published so far [1-10]. However, for the development of microgrid control and management functions, different simulation studies and tests have been performed [11, 12]. Different kinds of vendor-defined microgrid controllers have already been developed and tested [13], but there is a lack of standardized tests for microgrid control [14]. One of the challenges with vendor-defined solutions is that they might not meet interoperability and grid-code requirements. Figure 1 presents the traditional impact of standardization on product development, illustrating the product's lifetime cycle and standardization phases [15]. Because of the phase of the standardization, it can be concluded that microgrid controllers are in the stage of "need for product standards to resolve issues." Despite this standardization situation, the different solutions for microgrid management are becoming increasingly global. 
However, the software upgradability of new products becomes more important as requirements (e.g., grid codes and standards) change. Standardization takes more time as products and solutions become more complex, while at the same time, technology development goes faster, and the need for new solutions becomes faster. Start-ups in particular will probably not wait for the final standards. Therefore, many standards could be obsolete when they are released and require an immediate upgrade process.

The standardization of microgrid control systems is intended to define the requirements for microgrids "regardless of topology, configuration or jurisdiction and to present the control approaches required from the distribution system operator and the microgrid operator" [1]. The IEEE Standard 2030.7 defines the functions that a microgrid control system must perform, and the IEEE Standard 2030.8 presents the testing procedures for adopting the functional specification of microgrid control systems. According to [1], a microgrid control system is defined as "a system that includes the control functions that define the microgrid as a system that can manage itself, operate autonomously, and connect to and disconnect from the main distribution grid for the exchange of power and the supply of ancillary services; it includes the functions of the Microgrid Energy Management System (MEMS); it is the microgrid controller if implemented in the form of a centralized system" $[1,2]$.

One requirement for microgrid controller functions is to provide flexibility services like ancillary services (AS) [1], which can be realized with a technical or market-based approach. Technical AS are related to, for example, the control of reactive power $(Q)$ flow between the DSO's and the TSO's networks. The testing approach of microgrid controllers should include definitions for the test scenarios, the performance metrics, and the testing environment, which can range from a fully simulated environment to real equipment installed in the field $[2,16]$. Figure 2 presents the coverage and fidelity of the different testing methods $[17,18]$. Pure simulation is utilized in the research stage and in a very early stage of product development. In controllerhardware-in-the-loop (CHIL) simulations, the controller is a real device, but everything else is simulated. In powerhardware-in-the-loop (PHIL) simulations, there are real power devices (e.g., photovoltaic units, loads, and storage) in addition to the controller.

Consequently, it is essential to build comprehensive test platforms for microgrid controllers that can perform the CHIL and PHIL simulations and the tests for different types of required functionalities $[1,2]$ to verify the proper operation of the functions of the developed microgrid controller. Besides, the test platform should be flexible so that it can serve different kinds of microgrids [4] with the purpose of

(i) Improving electricity supply reliability and network resilience by intentional islanding

(ii) Providing power to remote areas with lower cost

(iii) Reducing the energy cost for microgrid users in grid-connected mode

(iv) Providing preparedness for disasters

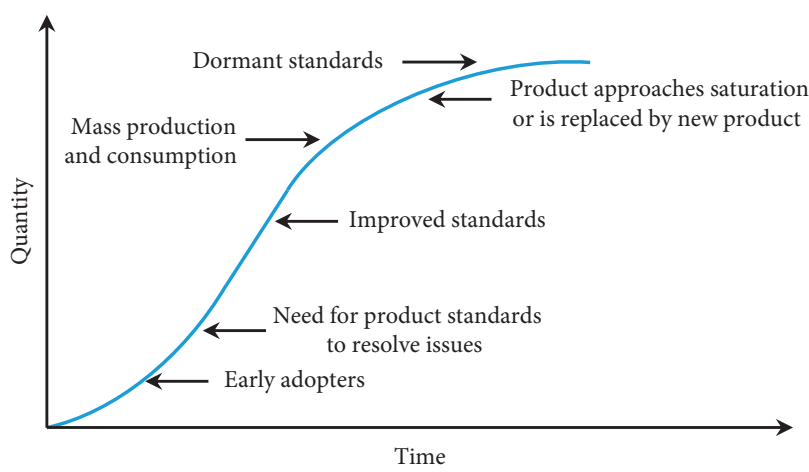

Figure 1: Product sales and standards cycle [15].

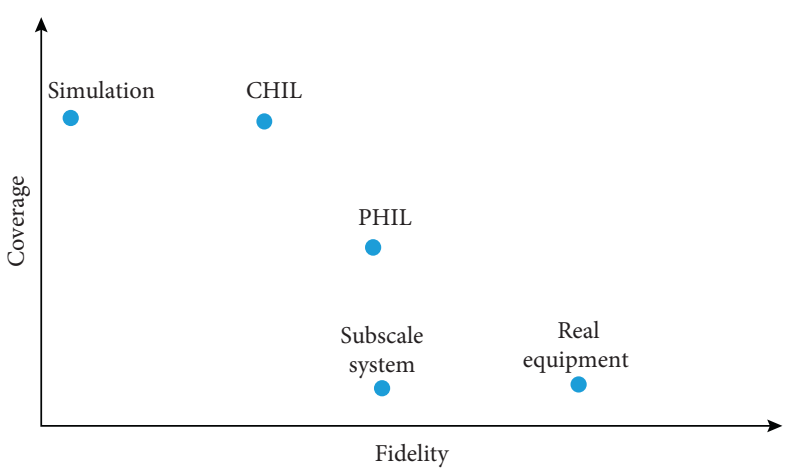

FIGURE 2: The coverage and fidelity of the different testing methods. Adapted from [17].

In HIL simulations, the Hardware under Test (HuT) is connected to the simulated system running in the real-time simulator or target. The real connection has delays and affects the stability of the system that has to be respected. In CHIL simulations, the delay consists of the target input/ output processing and communication time delay/latency as well as processing time of the controller [19]. The effect of the delay should be taken into account when tuning controller control parameters. Further, in PHIL simulations, the error is caused by delays and distortion introduced by the power interface. Moreover, the power amplifier between the power hardware and the target (the real-time simulator) may cause the system to be unstable. Therefore, it is essential to develop an interfacing algorithm between the target (simulated system) and the HuT. In addition to the previous ones, the utilized sample time of the real-time simulation has a major impact on the stability behaviour. $[18,20]$.

Based on the literature review on selected CHIL testbeds [21-24] and PHIL testbeds [25] suitable for microgrids, transition and dispatch function in power balance management and ancillary services are of great interest. The focus of [21-24] is on implementing control algorithms on hardware and stability issues. Long-term case studies in simulations are lacking. The authors in [22] present the results of a software controller for dynamic power-sharing with three PV units in islanded microgrid operation in which the PV generation profiles are represented in one-day historical data. The time scale was compressed into $14 \mathrm{~min}$ in real-time simulations, but analysis of the method and the 
effect of delays are not presented. New kinds of algorithms, computational techniques, or models could be developed for accelerating long-term simulations.

The focus in this paper is on developing an accelerated real-time cosimulation and a testing platform and setup, especially for long-term simulations. Furthermore, the aim is to test controller behaviour in the accelerated real-time simulations, in which the feasibility of the platform is evaluated. This kind of platform is novel; we did not come across any similar solution in the literature. The platform is planned to be utilized for the development and testing of microgrid controller ANM functions for microgrids in the grid-connected mode, particularly for long-term case studies. The long-term simulations are needed in order to study, for example, the potential weekly, monthly, or yearly usage and operation of distribution-network-connected DER for different technical flexibility services. The simulation setup developed consists of the real measurement data from the Sundom Smart Grid (SSG), a simulated power grid, communications, control functions, and a controller.

In the next section, Sundom Smart Grid (SSG), the SSG, and the different requirements for the reactive power flow are presented. After that, the section "The Real-Time Cosimulation Platform" presents the developed real-time cosimulation platform. The different simulations, executed tests, and experiments with the developed platform are presented in the section "Executed Tests and Experiments." The final section is "Conclusions and Discussion."

\section{Sundom Smart Grid (SSG)}

Figure 3 presents the SSG, which is a pilot of a local MVnetwork-based smart grid created in cooperation with $\mathrm{ABB}$, Vaasan Sähköverkko (DSO), Elisa (communications), and the University of Vaasa [27]. The SSG enables the development of AS solutions for future grids beyond the traditional boundaries from the HV level to the LV level. In the SSG, there are four MV feeders, and one feeder (J08) is only for the wind turbine (WT). Real-time IEC 61850 generic object-oriented substation event (GOOSE) measurements and sampled value (SV) measurements are gathered online from all the four feeders at the HV/MV substation, as well as from three MV/LV substations with 20 measurement points. For future research purposes, the measurement data are collected in servers.

The different requirements for the reactive power flow between the MV and HV networks in the SSG studied, with several requirements and targets, are presented in [28]. In Europe, the European Network of Transmission System Operators for Electricity (ENTSO-E) sets grid-code requirements, for example, for connection of demand facilities and generators $[29,30]$. Moreover, the national TSO has set requirements for the DSO's reactive power flow by a "reactive power window" [31] at the point of interconnection (POI), that is, between the TSO and DSO networks. The reactive power window (RPW) specifies the amount of reactive power that can be exported to the HV network and imported from the HV network without separate compensation. This RPW requirement and related compensation tariff aim to optimize the reactive power flow from the transmission network's point of view. In addition, reliable and future-proof islanding detection, as well as the possibility of making a stable transition to islanded operation, can be considered simultaneously with the reactive power flow control between HV and MV networks [26, 32-34].

Based on the results presented in [35], there would be an $80 \mathrm{k} €$ yearly cost for the DSO, caused by the capacitive reactive power flow generated by the cables in the SSG. In [36], the use cases and future scenarios for reactive power management are developed further to study and develop the RPW controller. The scenarios studied are Scenario 2018, Scenario 2028, and Scenario 2035.

\section{The Real-Time Cosimulation Platform}

The utilized real-time simulation platform is based on an OPAL-RT system consisting of power system simulations with ePHASORSIM (transient stability, phasor mode), as well as control and communications with eMEGASIM (electromagnetic transients, discrete type). Communication between the controller and the interfaces of the simulated power system is implemented with IEC 61850 GOOSE messages on Ethernet. Figure 4 presents an outline of the platform.

In previous researches $[19,36]$ for software-in-the-loop (SIL) simulations, a GOOSE publisher block is implemented in the real-time simulation model to publish (send) the measured active power $\left(P_{\text {meas }}\right)$ and the measured reactive power $\left(Q_{\text {meas }}\right)$ from the target (OP5600 simulator). Furthermore, a GOOSE subscriber block is implemented to subscribe (receive) the $P_{\text {meas }}$ and $Q_{\text {meas }}$ values from the Ethernet network. For the CHIL tests, a GOOSE subscriber and publisher are implemented in the hardware under testing, in addition to the RPW control algorithm. The implementation process is presented in [19], in which the simulation time step $\left(T_{s}\right)$ is $0.01 \mathrm{~s}$ for the real-time SIL and CHIL simulations. The results gathered by the real-time target are the hourly average active and reactive powers $\left(P_{\text {HVavg }}\right.$ and $\left.Q_{\text {HVavg }}\right)$, the instantaneous active and reactive powers $\left(P_{\mathrm{HV}}\right.$ and $\left.Q_{\mathrm{HV}}\right)$, the active and reactive powers from WT $\left(P_{\mathrm{WT}}\right.$ and $\left.Q_{\mathrm{WT}}\right)$, and the bus voltages. The CHIL tests are performed for the BeagleBone Black (BBB) as well as for the field-programmable gate array (FPGA) controllers. The IEC 61850 GOOSE message packets traveling over the network are captured by Wireshark software (.pcap files) from the traffic between the controller and the target. The results in [19] show that FPGA controllers are more efficient for future microgrid controller studies.

\section{Executed Tests and Experiments}

In this research, the parameters for reliably performing the accelerated real-time simulations are defined and analyzed by testing the improved RPW control algorithm [36]. The offline SIL, real-time SIL, and CHIL tests are performed with the parameters defined in the platform developed in [19] in order to determine how the real-time simulations could be accelerated, what kind of phenomena can occur, and when 


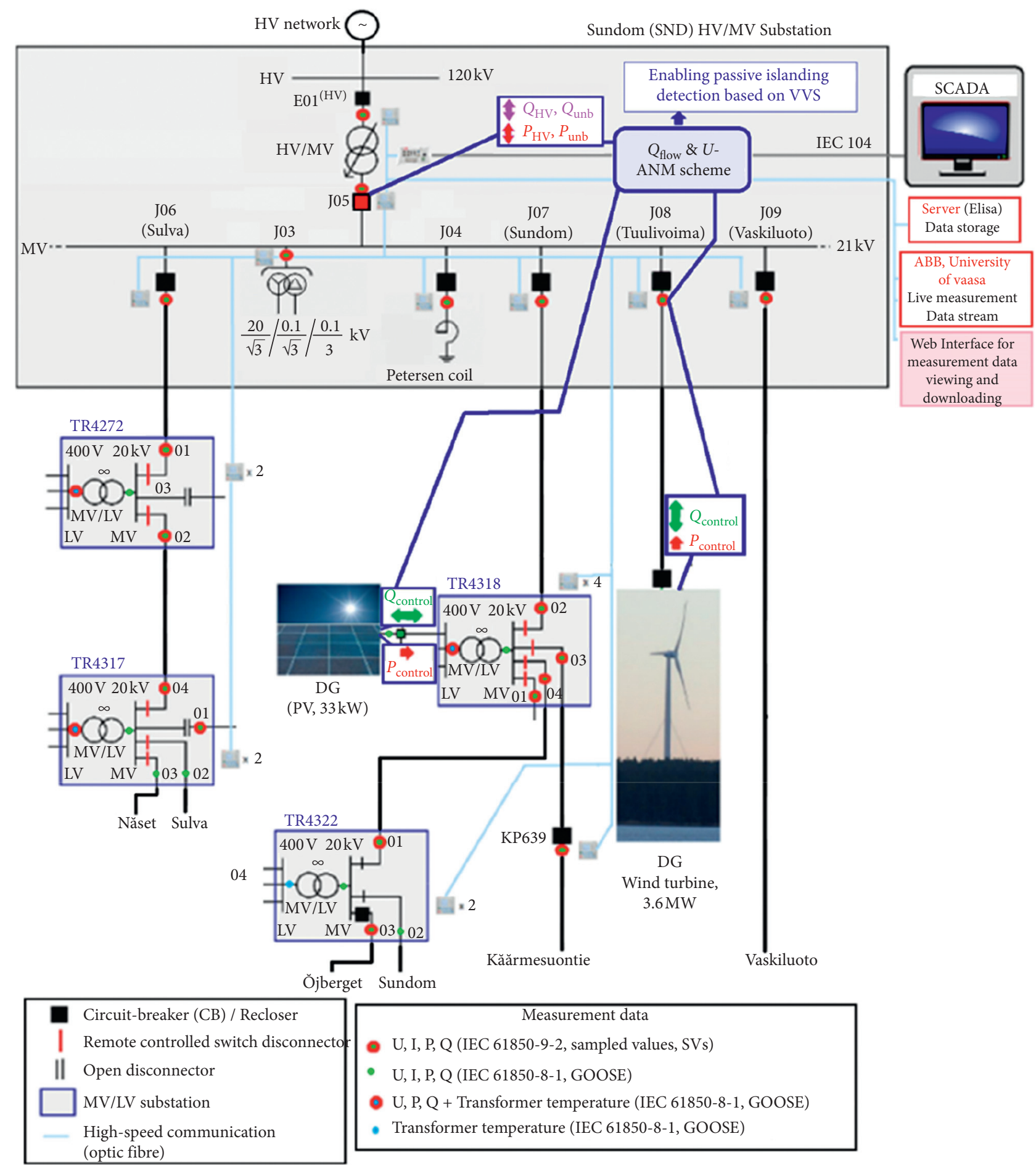

Figure 3: Sundom Smart Grid [26].

the results are reliable. The results from the real-time SIL and CHIL tests should correspond to the offline SIL results when there are no communication and hardware processor delays.

In this study, the simulations are performed with the controller limits set according to Figure 5. The limits for the controlled values are set $\pm 50 \mathrm{kVAr}$ tighter, except $\mathrm{QD} 1=\mathrm{Qi}+200 \mathrm{kVAr}$ for the controller of the WT converter. In other words, the controller operation (a trigger for calculating a setpoint value for the WT converter) limits are the TSO limits (the red limits), but the setup limits for the WT converter are set tighter (the blue limits).

The offline SIL simulations, as well as the real-time SIL and CHIL tests, are presented below. In order to run longterm power flow simulations, for a one-year period, in this case, the simulations are accelerated by implementing the input-data-reading step from the 


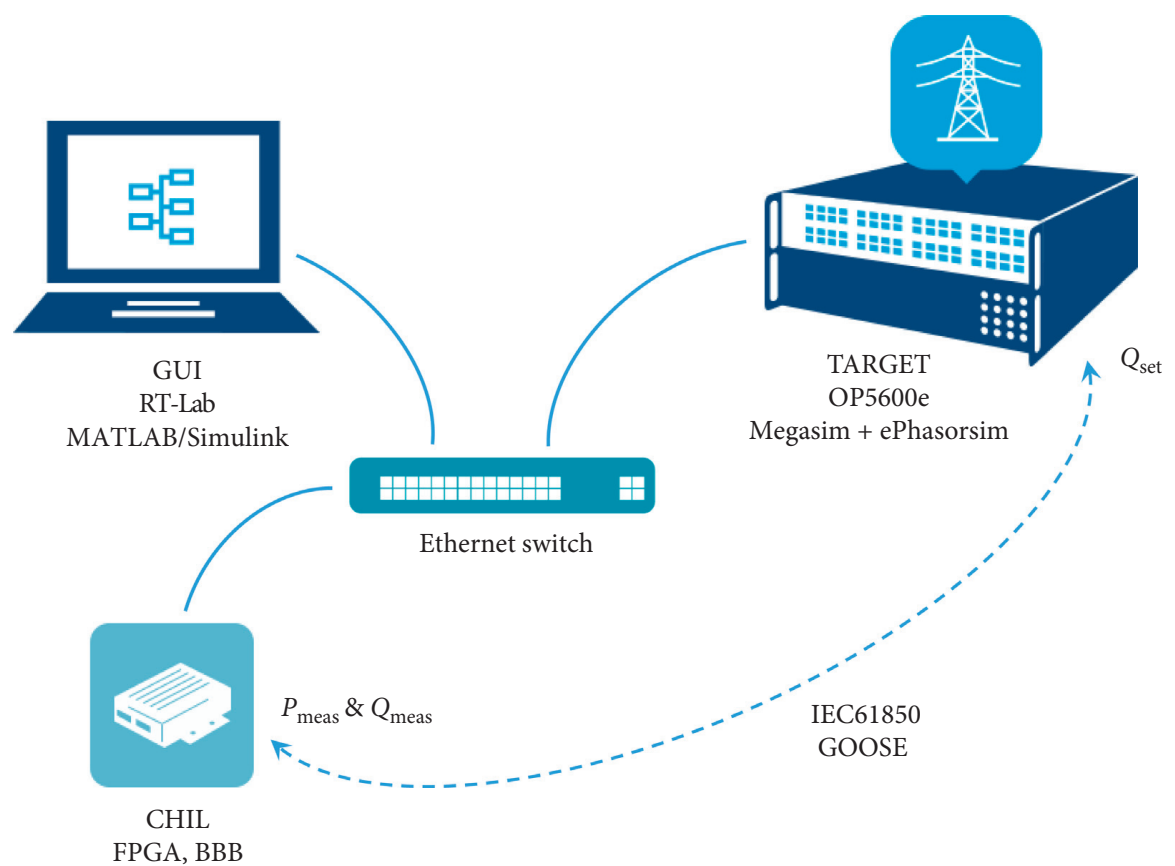

FIgURE 4: The real-time cosimulation platform [36].

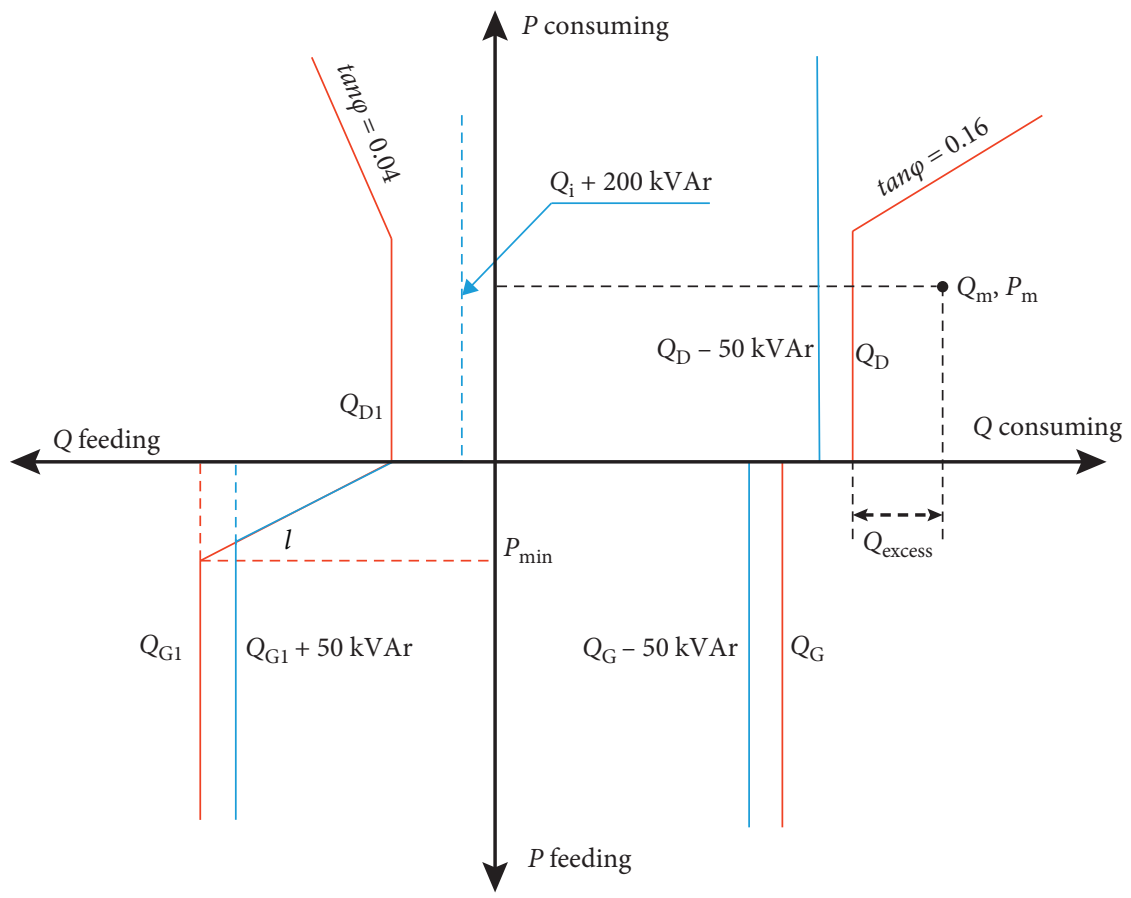

TSO's limits = RPW controller operating limits Desired value

FIgURE 5: The setup for the controller limits.

OpFromFile block. This block reads from a Matlab file (.mat) and outputs the samples from the file. Further, the time factor, coefficient $T_{d}$, for reading a data row from the input data (in this case, the hourly average values over one year from the SSG) or the look-up table is set so as to correspond to the reading step of the one-hour input data. The aim of this study is to test different values for $T_{d}$ to find a value that does not distort the results, that is, answering the question of how much the real-time simulations can be accelerated. For the one-year simulation, the hourly average values of the one-year measurements as input data generate 8760 rows of data, and the coefficient $T_{d}$ is set accordingly to find the initial range for which the results are reliable. 
Generally, the use of accelerated simulation would mean the modification of the models so that their behaviour in the accelerated time scale is equivalent to the behaviour in realtime scale. This means that the modified model is dimensionally similar. In this study, this kind of approach would have meant overly complicated modifications to the models, so another approach was used. Instead, the original time-scalebased models were used with a suitable selection of the simulation time steps so that the desired outcome was reached.

The cosimulation platform and the concept are presented in more detail in Figure 6. Different simulation time steps are also shown in Figure 6 , where $T_{\mathrm{s}}=0.01 \mathrm{~s}$ represents the simulation time step both for the simulated power system in ePHASORSIM and for the measurements, PI/I control, and so forth in eMEGASIM. Further, $T_{d}$ represents the time step for the reading cycle of the input data $\left(\mathrm{PQ}_{\text {load }}\right.$ and $\mathrm{PQ}_{\mathrm{gener}}$ ation). $T_{c}$ represents the time step for reactive power setpoint $\left(Q_{\text {set }}\right)$ value calculation in the RPW controller.

The involved time steps and the limiting factors of the system are the following:

(1) Simulation time step $T_{s}$ is the same for the SIL $\left(T_{s, m}\right)$ and CHIL $\left(T_{s, p}\right)$ setups: $T_{s, m}=T_{s, p}=T_{s}=0.01 s$.

(2) Data reading cycle $T_{d}$ is the same for the SIL $\left(T_{d, m}\right)$ and CHIL $\left(T_{d, p}\right)$ setups.

The input data reading cycle has to be defined so that it enables maximum acceleration of the simulated system, while the results are not disrupted. The results can be proved with the equivalent results from offline SIL and real-time SIL as well as from the CHIL tests. In addition, the input data reading cycle based on the (measurement) data type has to be selected for real-time tests, so that reasonable computation times are achieved.

(3) RPW controller operating time step $T_{c}$ in the SIL $\left(T_{c, m}\right)$ and CHIL $\left(T_{c, p}\right)$ setups.

$T_{c, m}$ for SIL controller can be selected as $T_{c, m}=n * T_{s}$, where $n$ is an integer. Controller operating time step $T_{c, p}$ for CHIL controller depends on the processor of the hardware; FPGA has DualCore ARM Cortex ${ }^{\mathrm{TM}}$ A9 $(925 \mathrm{MHz})$ processor, whereas the BBB has AM335 × $1 \mathrm{GHz} \mathrm{ARM}^{\circledR}$ CortexA8.

Both of these hardware controllers were fast enough, not limiting the accelerated CHIL tests in this case. Within one simulation time step, $T_{s}$, they were able to receive $\mathrm{P}_{-} \mathrm{HV}$ and $\mathrm{Q} \_\mathrm{HV}$ values, process the new setpoint value $\mathrm{Q}_{\text {set}}$, and send it back to real-time simulator.

(4) I or PI controller operating time step: the I or PI controller operation depends on the defined sampling time for it. In this study, the sampling time is the same as the simulation time step $T_{s}$.

(5) Acceleration.

In this case, an input data $\left(D_{e}\right)$ row represents the one-hour average value of active power, and the output values thus represent hourly averages. The data type could also be, for example, $10 \mathrm{~min}$ average $\left(D_{10 \mathrm{~min}}\right)$ or $5 \mathrm{~min}$ average $\left(D_{10 \mathrm{~min}}\right)$ keeping in mind that acceleration:

$$
A=\frac{D_{e}}{T_{d}} .
$$

The electricity network model is running in real time with $T_{s}=0.01 \mathrm{~s}$, which is selected so that the transient phenomena have time to decay, and the system has reached steady state before new input data is read with time steps $T_{d}$ of $0.1 \mathrm{~s}$ or more.

Table 1 presents the coefficients and the effects of their values. For example, in Option 1 , selecting $T_{d}=0.1$ means that a one-year accelerated real-time simulation will take $876 \mathrm{~s}$ (around $15 \mathrm{~min}$ ) with one-hour average input data. Further, the simulation time step $T_{s}=0.01 \mathrm{~s}$ is equivalent to $360 \mathrm{~s}$ in real-world time, which means that the power flow of the system is known in intervals of $360 \mathrm{~s}$. Option $29\left(T_{d}=20\right)$ presents the setup in which the power flow would be calculated every $1.8 \mathrm{~s}$ (representation of the real-world time). In this case, the accelerated real-time simulation would take 49 hours. The time step for the RPW controller action, $T_{c}$, could be selected in SIL, which is also presented. The selection of $T_{c}$ mimics how often the RPW controller can calculate a new setpoint if desired, and $T_{s}$ determines when the potential new setpoint value comes into effect for the WT converter. In the following sections, the evaluation of the suitable initial coefficients for accelerated real-time simulations is presented with the results from the offline simulations.

4.1. Offline SIL Tests. Several offline SIL tests are performed to define the initial coefficient $T_{\mathrm{d}}$ for the accelerated realtime simulations. The comparisons of the results between Option 1 and Option $6\left(T_{d}=0.1\right.$ and $\left.T_{d}=1\right)$, as well as between Option 6 and Option $24\left(T_{d}=1\right.$ and $\left.T_{d}=10\right)$, are presented in Figure 7. It can be seen that there is a difference between both comparisons due to the different $T_{d}$ values, which means that the smaller values $(0.1$ and 1$)$ are not suitable. For the next trial, the comparisons of the results between Option 14 and Option $24\left(T_{d}=5\right.$ and $\left.T_{d}=10\right)$, as well as between Option 9 and Option $14\left(T_{d}=4\right.$ and $\left.T_{d}=5\right)$, are made, and it can be observed that no difference exists between the results. The latter result indicates that a suitable initial $T_{d}$ coefficient is $\geq 4$.

By examining the results more closely, one can see that a difference in results emerges around $4000 \mathrm{~h}$ and later. Figure 8 shows that time point in more detail with different $T_{d}$ values. When $T_{d}$ is 0.1 or 1 and even when $T_{d}$ is 5 or 10 , $Q_{\mathrm{WT}}$ was "oscillating" in the time period between $4031 \mathrm{~h}$ and $4032 \mathrm{~h}$. The oscillation form, that is, the amplitude of the oscillation, is increasing, which illustrates that the system is in an unstable region during that hour. Further, when $T_{d}$ is smaller, the value of $Q_{\mathrm{WT}}$ after this oscillating hour is different. When $T_{d}=0.1, Q_{\mathrm{WT}}=-0.2213 \mathrm{MVAr}$, and when $T_{d}=1, Q_{\mathrm{WT}}=-0.2305$ MVAr. These observations explain the difference in downstream results (after $4032 \mathrm{~h}$ ). When $T_{d}$ is 5 


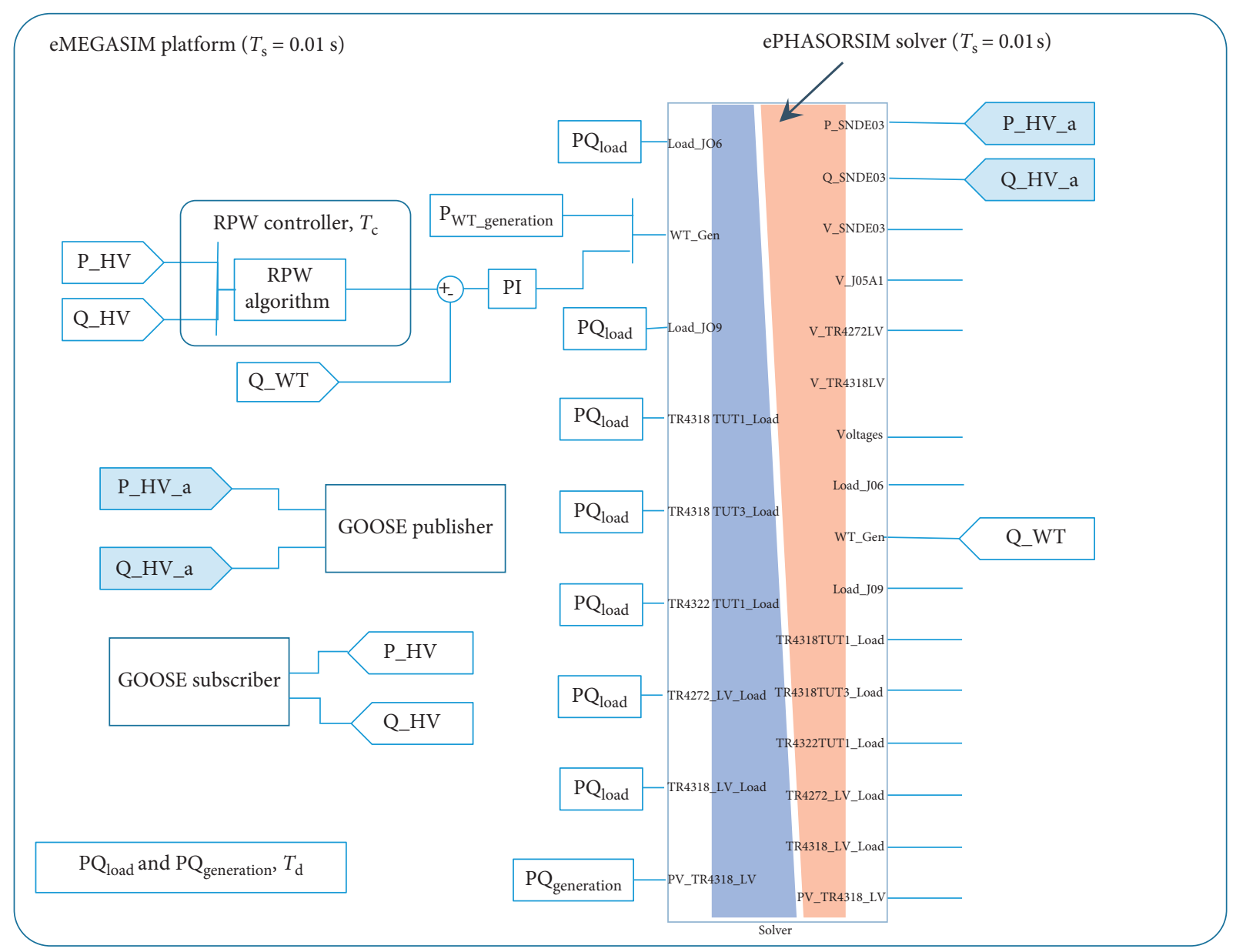

FIGURE 6: The emulated system and the RPW controller.

or 10, the oscillation also occurs, but now the resulting $Q_{\mathrm{WT}}$ is the same (-0.3103 MVAr).

This oscillation phenomenon is presented more closely in Figure 9. At $t=403100$, the point $\left(Q_{\mathrm{HV}}, P_{\mathrm{HV}}\right)$ is inside the window (0.7982 MVAr, 4.9824 MW), consuming active and reactive power, while the reactive power of the WT converter is capacitive, $Q_{\mathrm{WTset}}=Q_{\mathrm{WTmeas}}=-0.1869 \mathrm{MVAr}$. In the next time step, $t=403101$, the "measured" point $\left(Q_{\mathrm{HV}}, P_{\mathrm{HV}}\right)$ is outside the window $\left(Q_{\mathrm{HV}}=0.9620 \mathrm{MVAr}_{\text {ind. }}, P_{\mathrm{HV}}=5.399 \mathrm{MW}\right)$ (the limit is $Q_{D}=0.83 \mathrm{MVAr}$ ) when $Q_{\mathrm{WTmeas}}=-0.1869 \mathrm{MVAr}$. Then, a new setpoint of the WT converter is calculated, $Q_{\text {WTset }}(t=403101)=-0.1820$ MVAr, which is realized by the control at the next time step, $t=403102$. However, at that moment, $Q_{\mathrm{WTset}}$ is not high enough, and $\left(Q_{\mathrm{HV}}, P_{\mathrm{HV}}\right)$ is outside the window (0.9994 MVAr, 5.4718 MW) again, while $Q_{\text {WTmeas }}(t=403102)=Q_{\text {WTset }}(t=403101)=-0.1820$ MVAr. This phenomenon occurs over a period of time, depending on the selected $T_{d}$.

After all, a new setpoint aims to influence the reactive power $Q_{\mathrm{HV}}$ by correcting the output of the WT converter so that the next $\left(Q_{\mathrm{HV}}, P_{\mathrm{HV}}\right)$ point will be inside the window. However, according to Figure 10, the RPW control is lagging a simulation step; that is, the new setpoint is calculated based on the last measurement of $\left(Q_{\mathrm{HV}}\left(t_{i-1}\right), P_{\mathrm{HV}}\left(t_{i-1}\right)\right)$. At this specific time, there is a possibility of having oscillations in the controlled system due to the delay of the control. This delay is dependent on two aspects: the selection of $T_{d}$ as well as the delay of the I or PI controller. The I or PI controller was used to prevent algebraic loops in the modelled system.

Above we stated that the total oscillation time is dependent on $T_{d}$. The effect of $T_{d}$ selection on the oscillation time is studied further in order to find a relationship. Figure 11 presents the results of the oscillation time in simulations with different values of $T_{d}$. Increasing the value of $T_{d}$ seems to decrease the total oscillation time $\tau_{T_{d i}}$. In addition, two other results are presented, one with an I controller and one with a PI controller. In both cases, $T_{\mathrm{I}}=99.5$ and $T_{c}=0.01$ are used for the I controller. For comparison, a PI controller with $K_{P}=1.2$ and $T_{I}=99.5$, as well as $T_{c}=0.02$, is investigated. The results are presented in Table 2 . Based on both these results, with a suitable initial value (in this case, $T_{d} \geq 4$ ), it can be derived that the total oscillation time decreases linearly in the ratio 


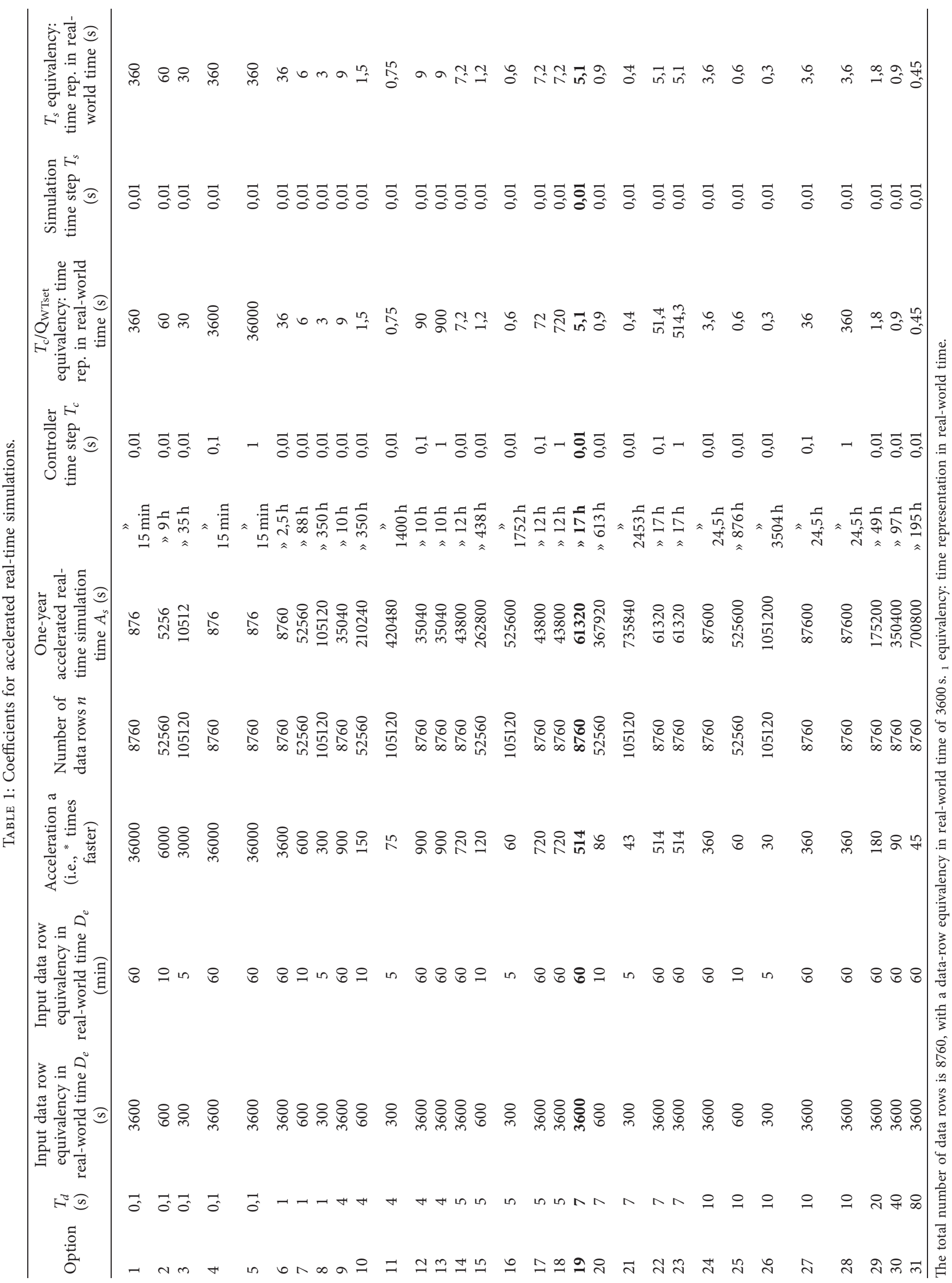




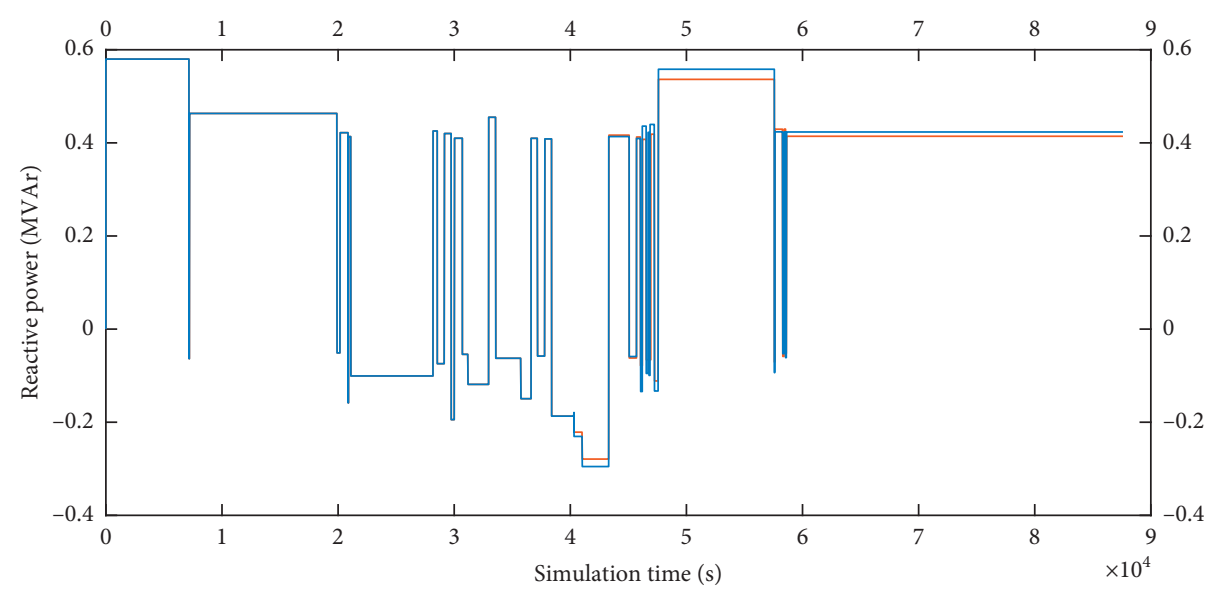

- SIL off, $\mathrm{Td}=0.1$

- SIL off, Td $=1$

(a)

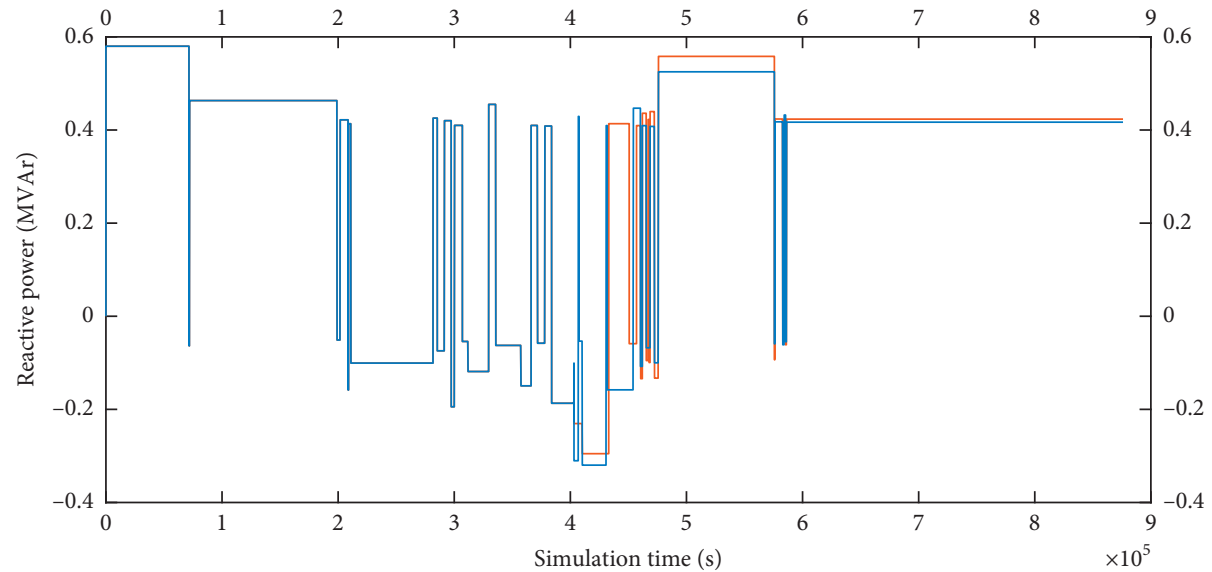

- SIL off, $\mathrm{Td}=1$

- SIL off, $\mathrm{Td}=10$

(b)

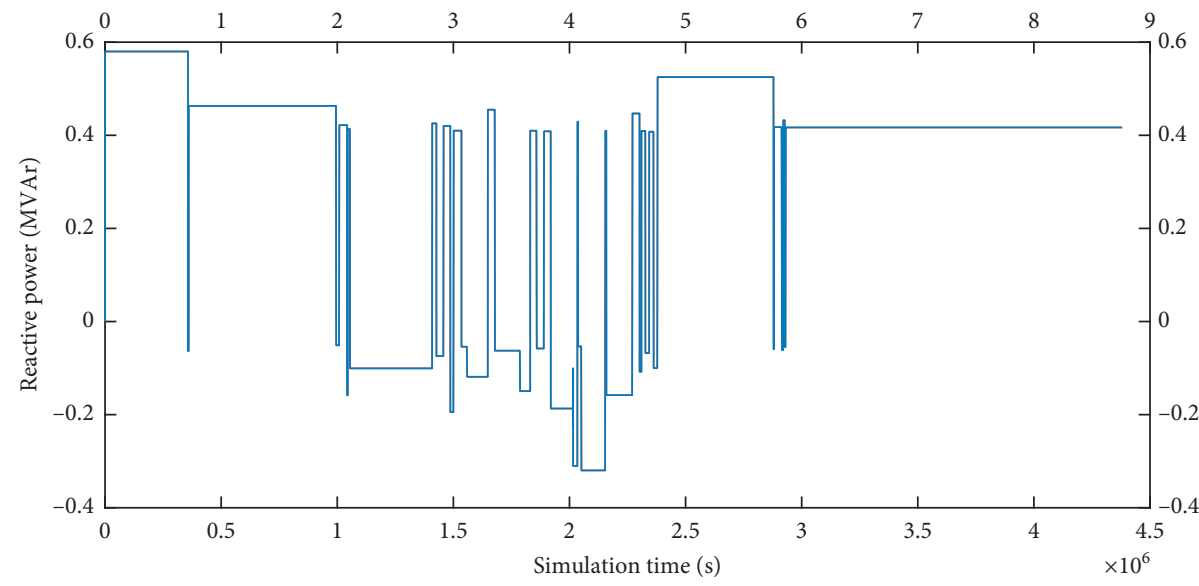

- SIL off, Td $=5$

SIL off, Td $=10$

(c)

Figure 7: Continued. 


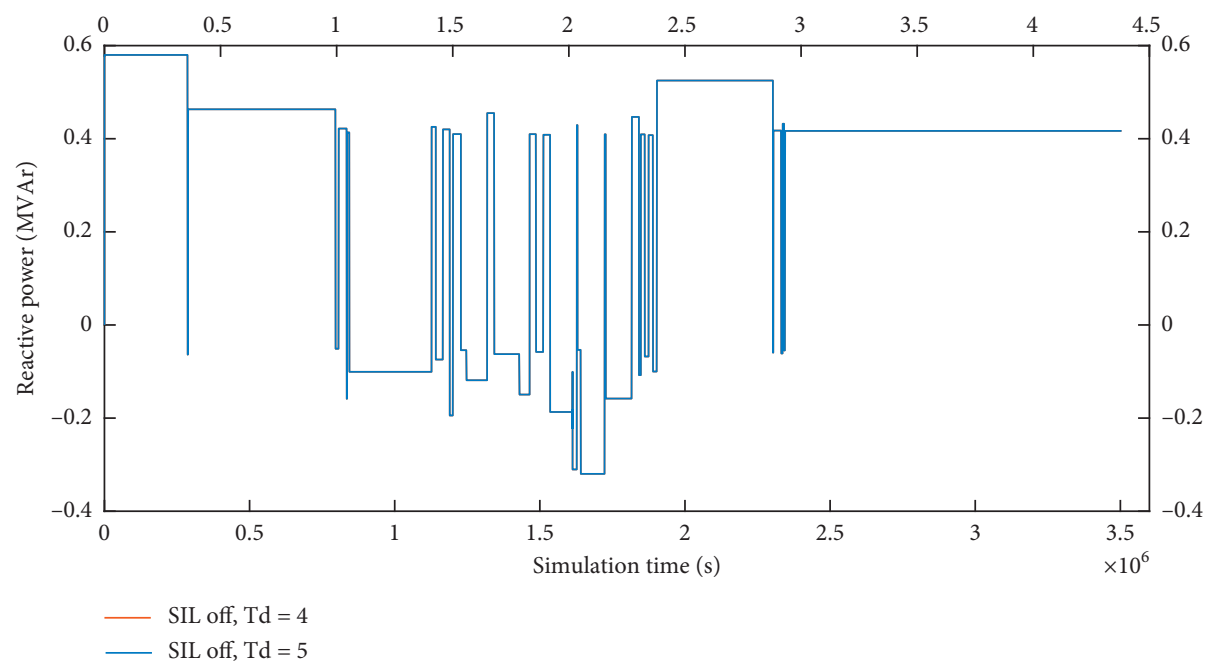

(d)

Figure 7: Results of the offline SIL simulations. Comparison of the reactive power of the WT converter when $T_{d}=0.1$ or $1, T_{d}=1$ or $10, T_{d}=5$ or 10 , and $T_{d}=4$ or 5 .

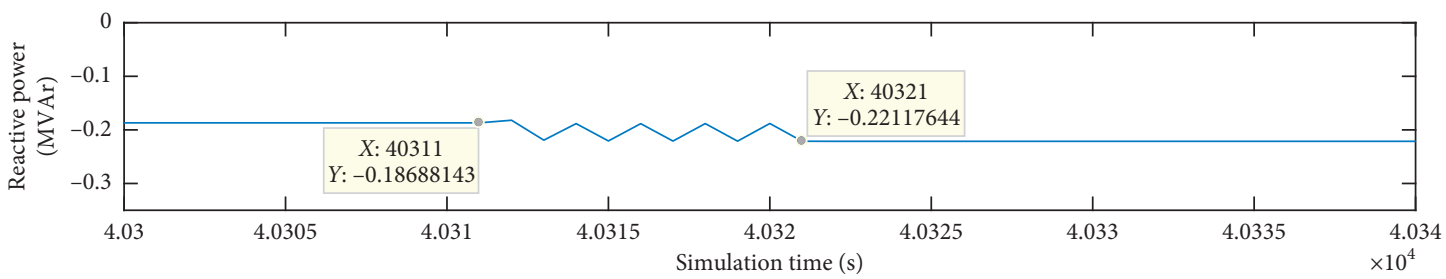

(a)

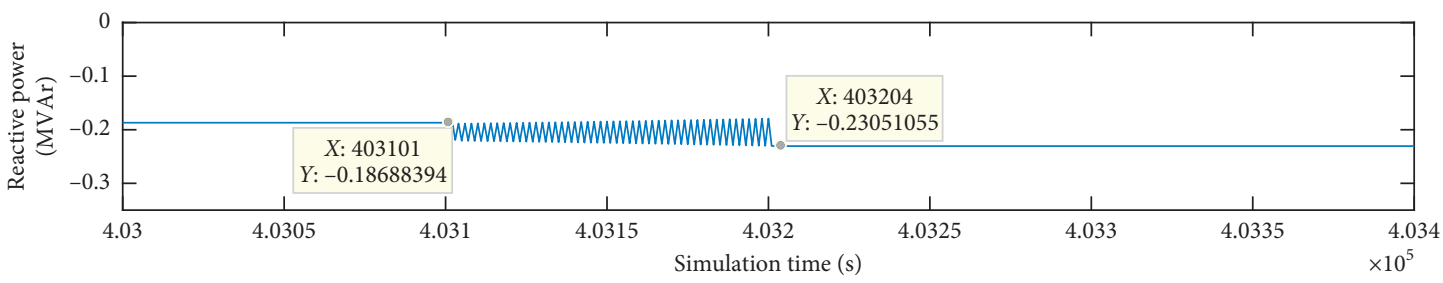

SIL off, $\mathrm{Td}=1$

(b)

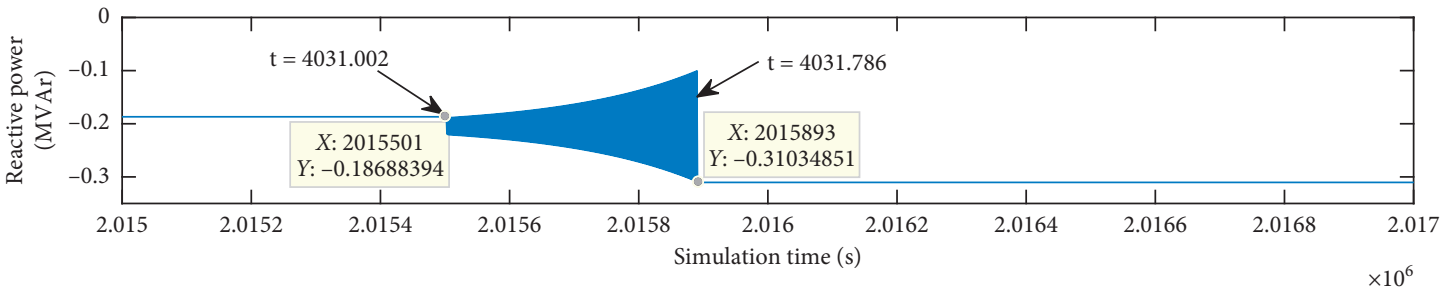

SIL off, Td $=5$

(c)

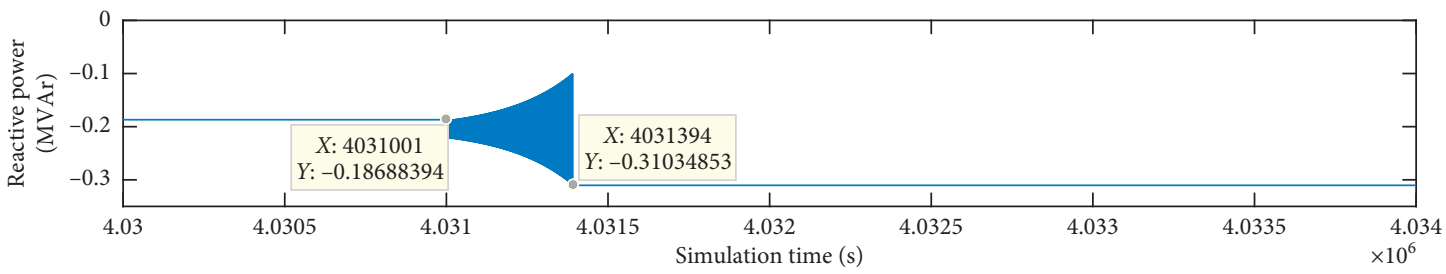

SIL off, Td $=10$

(d)

FIgUre 8: Results of the offline SIL simulations. Reactive power of the WT converter when Td was 1, 0.1, 5, or 10. The possible "oscillation" moment. 


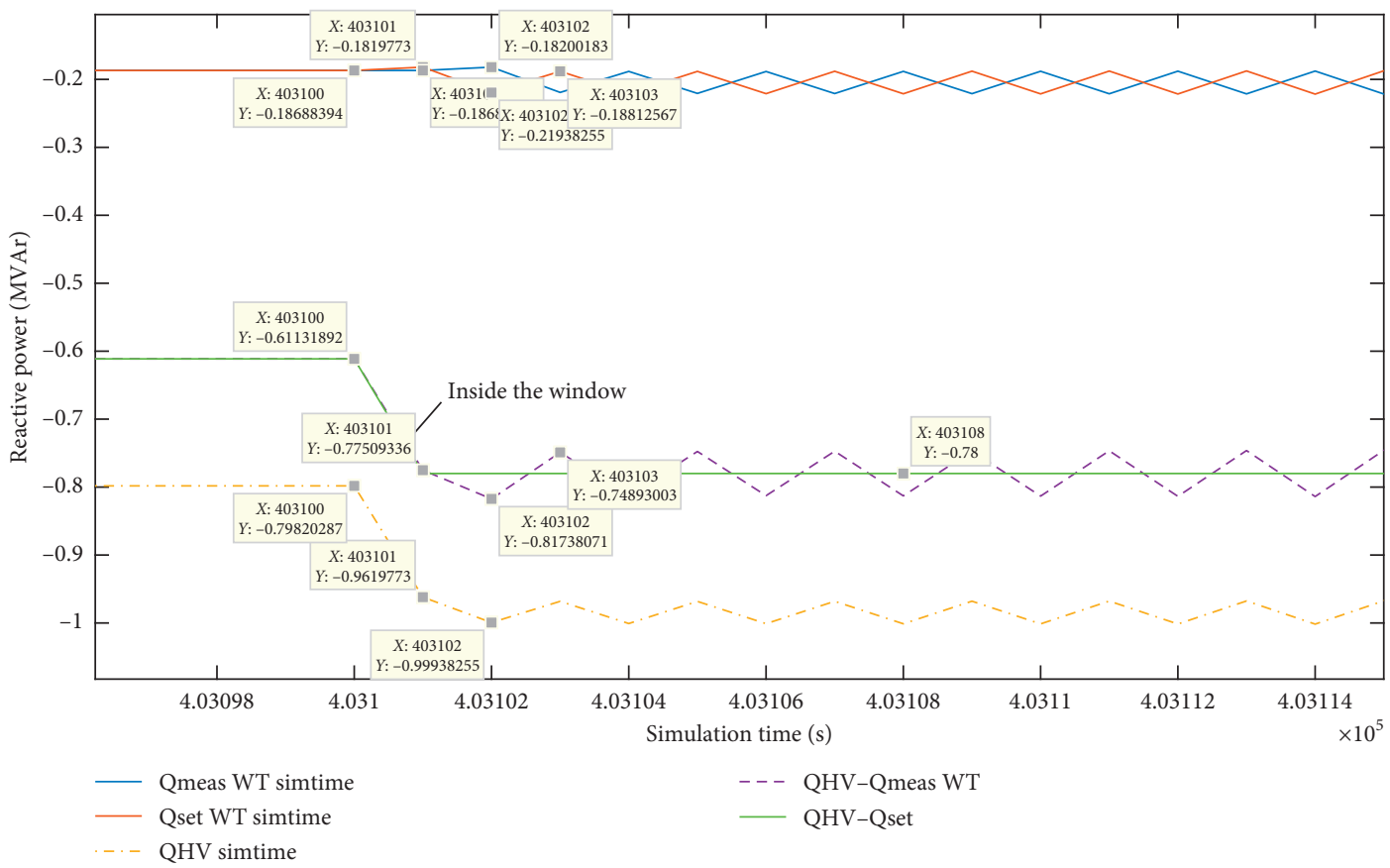

FIgURE 9: Oscillation investigation when $T_{d}=1$.

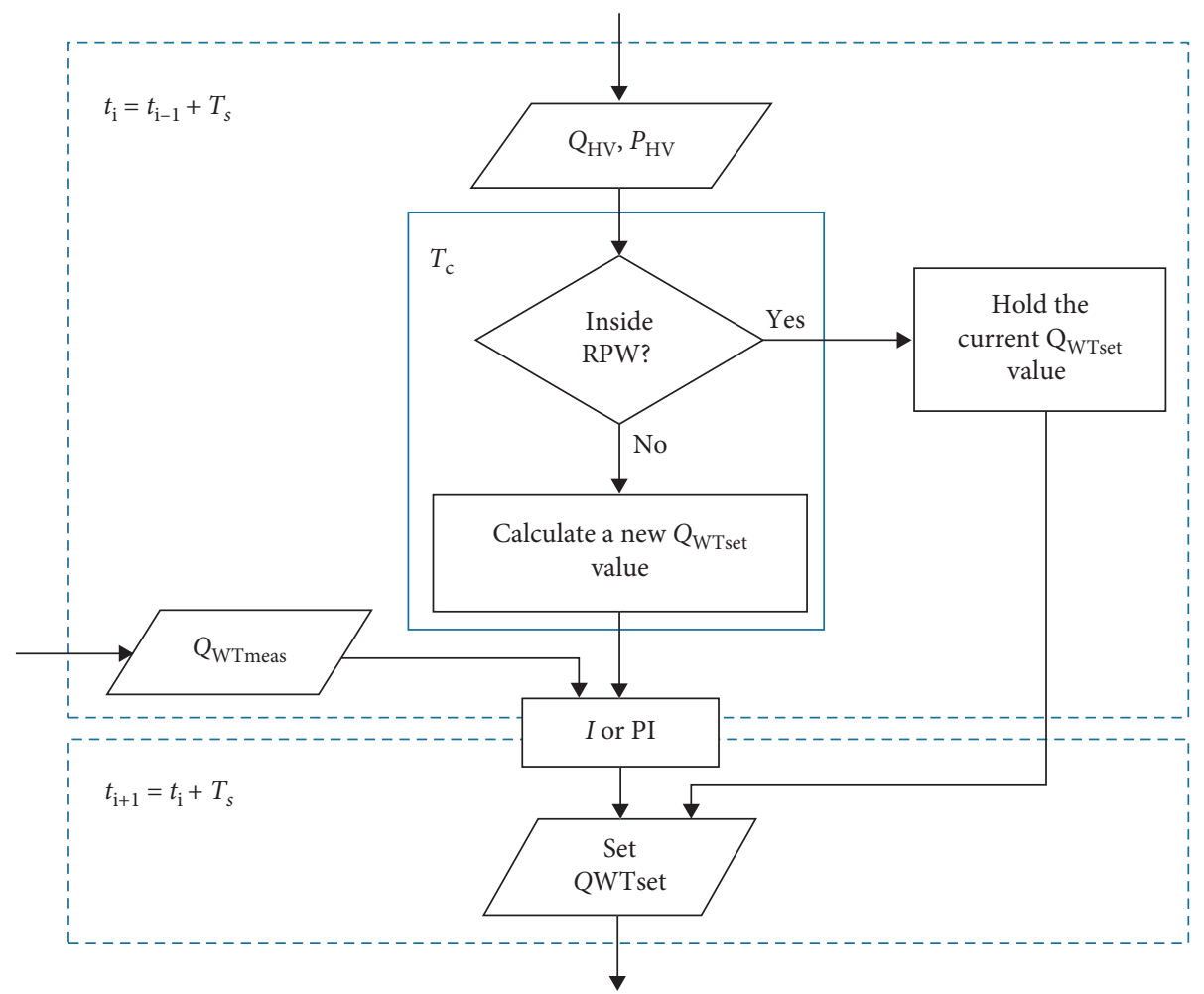

FIGURE 10: Flow chart of the RPW controller.

$$
\tau_{T_{d, i}}=\frac{1}{T_{d, i}} \tau .
$$

Based on equation (2), the oscillation time in real-world time would be $1.3 \mathrm{~s}$ in the I-controller case and $3 \mathrm{~ms}$ in the PI-controller case.
The above oscillation phenomenon occurs in accelerated simulations. However, it was found that the duration of the oscillation decreases when $T_{d}$ increases or becomes closer to real time. The evaluation of how the $P$ and $I$ parameters depend on the accelerated real-time simulation could be a future research topic. 


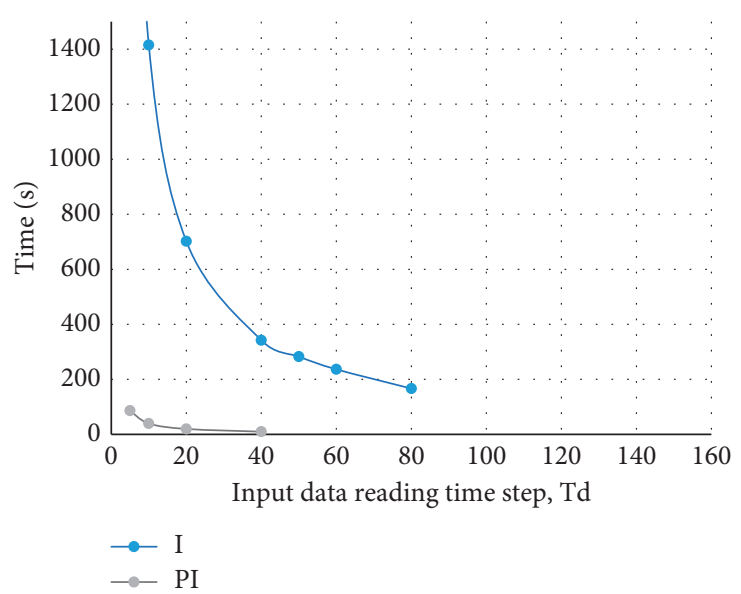

FIgURe 11: Duration of oscillation.

TABLE 2: Oscillation duration.

\begin{tabular}{|c|c|c|}
\hline$T_{\mathrm{d}}$ & Oscillation duration [s]: case $T_{\mathrm{c}}=0.01, I=99.5$ & Oscillation duration [s]: case $T_{\mathrm{c}}=0.02, P=1.2, I=99.5$ \\
\hline 0,1 & 3600 & \\
\hline 1 & 3708 & \\
\hline 5 & 2822,4 & 86,4 \\
\hline 10 & 1414,8 & 39,6 \\
\hline 20 & 702 & 19,8 \\
\hline 40 & 342 & $9,9^{*}$ \\
\hline 50 & 282,888 & \\
\hline 60 & 236,4 & \\
\hline 80 & 166,5 & $4,95^{*}$ \\
\hline 160 & $83,25^{*}$ & $2,475^{*}$ \\
\hline 320 & $41,625^{*}$ & $1,2375^{*}$ \\
\hline 640 & $20,8125^{*}$ & $0,61875^{*}$ \\
\hline 1280 & $10,40625^{*}$ & $0,309375^{*}$ \\
\hline 2560 & $5,203125^{*}$ & $0,1546875^{*}$ \\
\hline 5120 & $2,6015625^{*}$ & $0,07734375^{*}$ \\
\hline 8760 & $1,30078125^{*}$ & $0,038671875^{*}$ \\
\hline
\end{tabular}

${ }^{*}$ Calculated values.

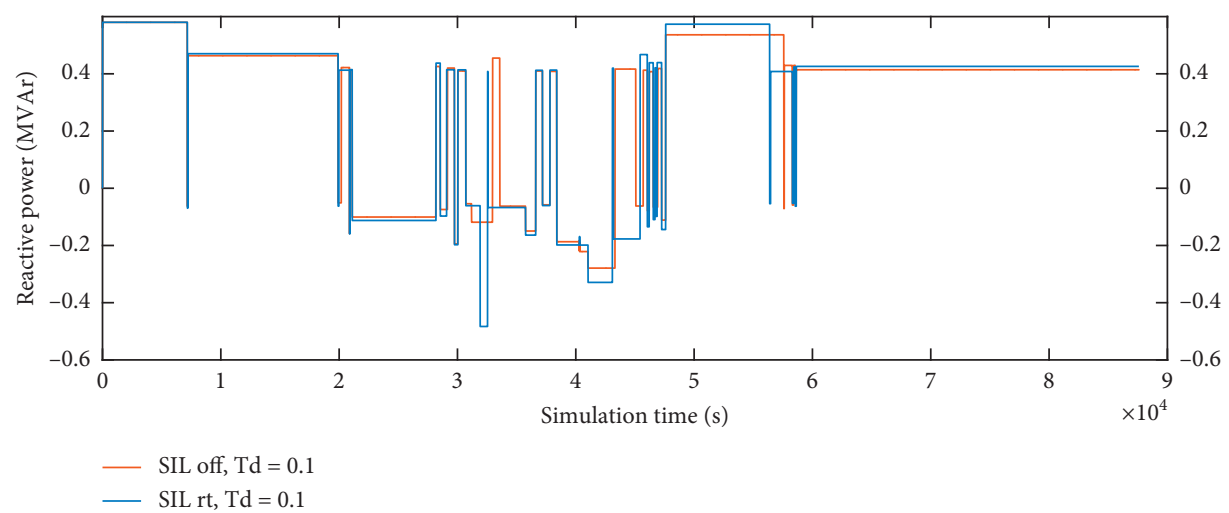

(a)

Figure 12: Continued. 


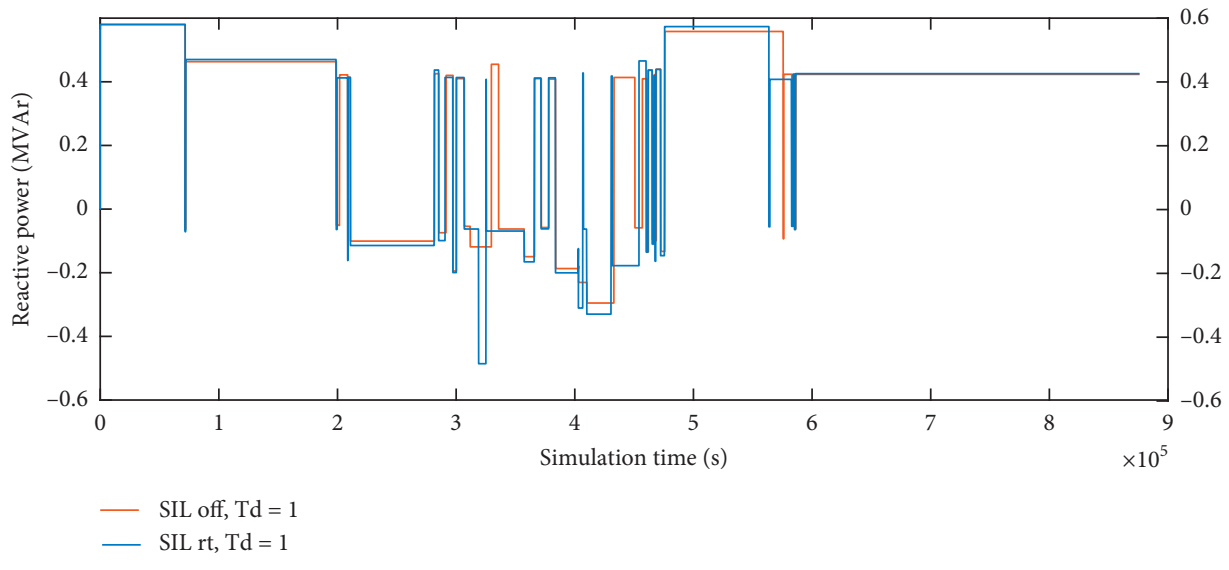

(b)

FIgURE 12: Results from the offline SIL and real-time SIL simulations. Reactive power flow of the WT converter when $T_{d}=0.1$ and 1 . The $\mathrm{RPW}$ controller was set up to the TSO limits of $\pm 50 \mathrm{kVAr}$, except $\mathrm{QD}_{1}=Q_{i}+200 \mathrm{kVAr}$.

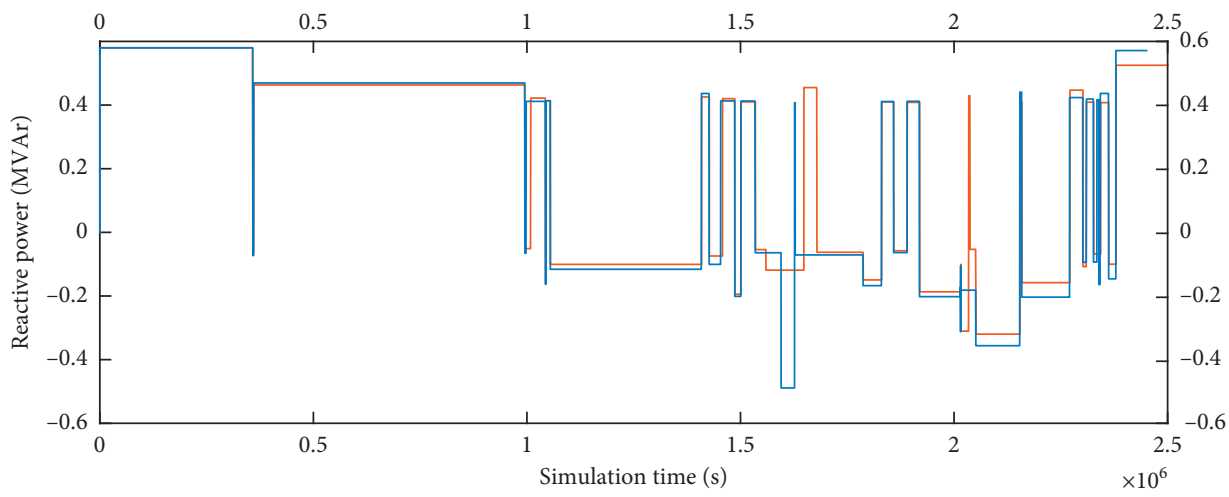

SIL off, Td $=5$

- SIL rt, Td $=5$

(a)

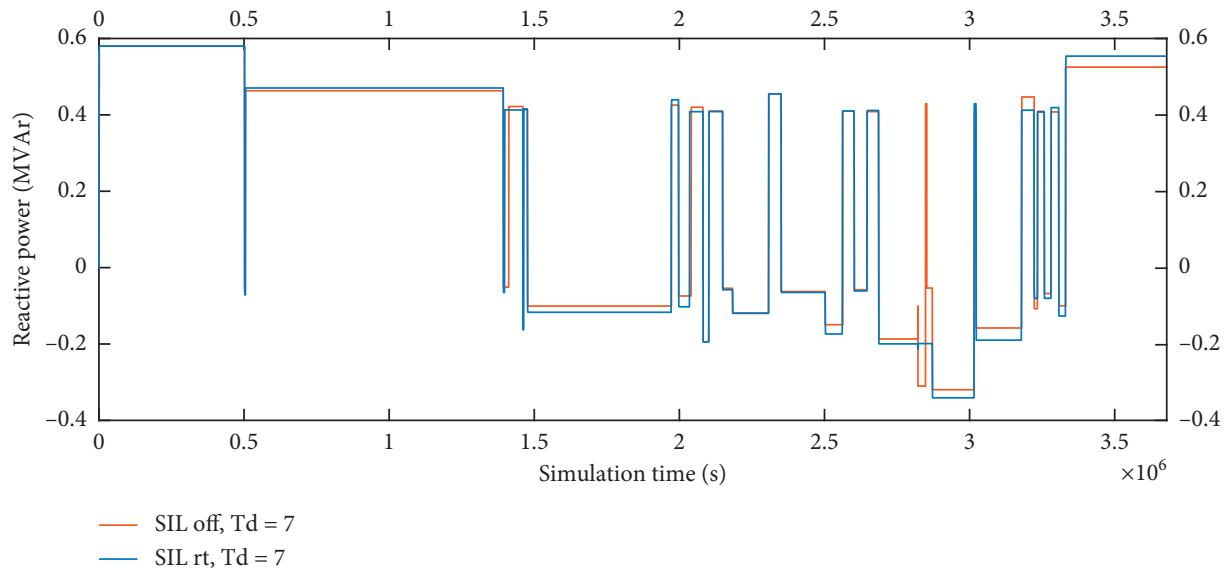

(b)

Figure 13: Continued. 


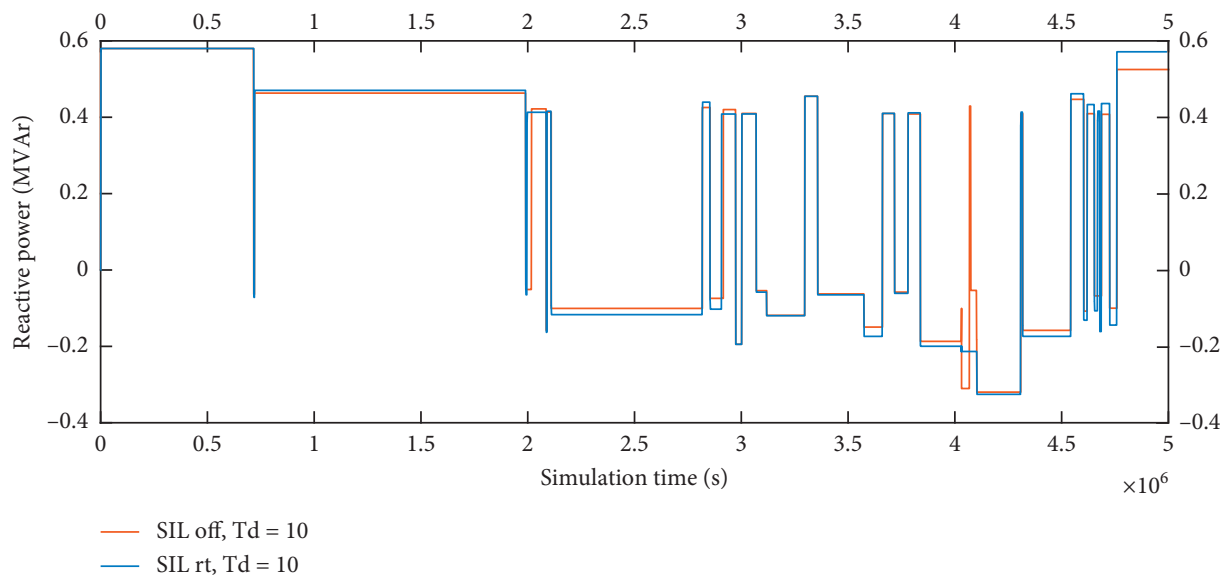

(c)

FIgURE 13: Results of the offline SIL and real-time SIL simulations. Reactive power flow of the WT converter when $T_{d}=5, T_{d}=7$, and $T_{d}=10$. The RPW controller was set up to the TSO limits of $\pm 50 \mathrm{kVAr}$, except $\mathrm{QD}_{1}=Q_{i}+200 \mathrm{kVAr}$.

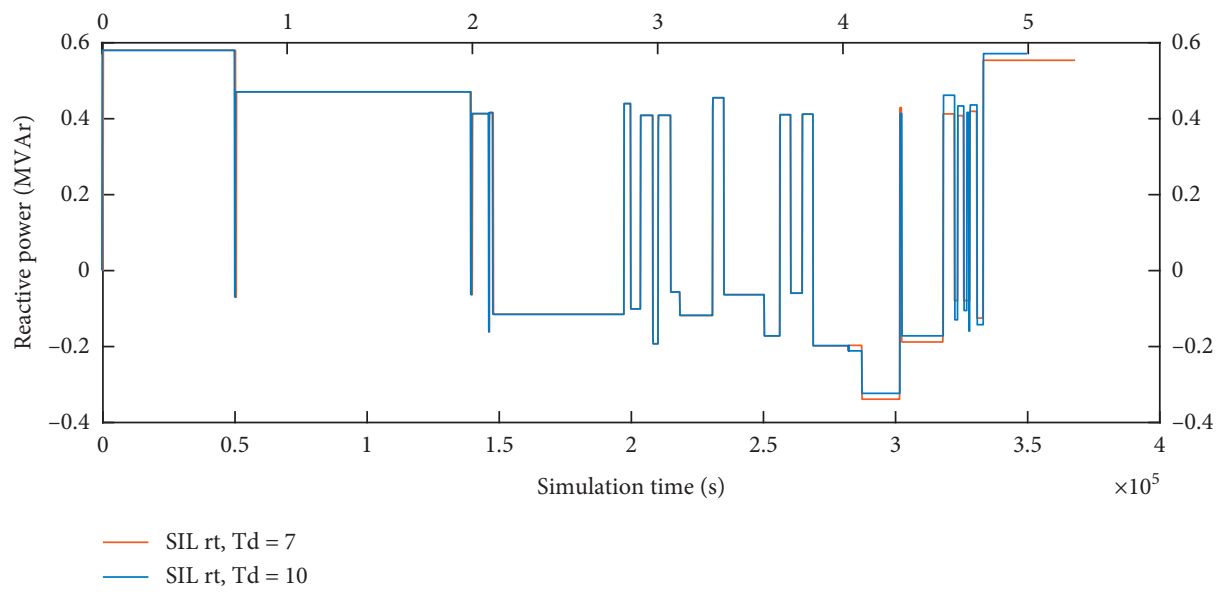

FIgURE 14: Results of the real-time SIL simulations. Reactive power flow of the WT converter when $T_{d}=7$ and $T_{d}=10$. The RPW controller was set up to the TSO limits of $\pm 50 \mathrm{kVAr}$, except $\mathrm{QD}_{1}=\mathrm{Q}_{i}+200 \mathrm{kVAr}$.

4.2. Real-Time SIL Tests. The first real-time SIL tests are performed with $T_{d}=0.1$ and $T_{d}=1$. The results are presented in Figure 12 by comparing them to the corresponding results of the offline SIL simulations. It can be observed that there are again small differences between both cases. This is due to the delay in communications.

Next, it is studied whether increasing $T_{d}$ decreases the difference between offline SIL and real-time SIL results, that is, whether it can eliminate the effect of the communication delay. Based on the offline results, $T_{d}>4$ could be a suitable value. The reactive power flows at the WT converter are presented in Figure 13 when $T_{d}=5$, $T_{d}=7$, and $T_{d}=10$. It can be seen that the results of the offline SIL and real-time SIL simulations are different when $T_{d}=0.1,1,4$, and 5, whereas the results look similar when $T_{d}=7$ or 10 . Based on the above, a suitable factor for real-time simulations could be $T_{d} \geq 7$. Figure 14 presents a comparison of the real-time simulation results when $T_{d}=7$ and $T_{d}=10$. It can be observed that now the results converge.
Further, the oscillating hour 4031 was investigated from a communication's point of view. Figure 15 presents the situation in which $T_{d}=1, T_{d}=5, T_{d}=7$, and $T_{d}=10$. Oscillations occur when $T_{d}=1$ and $T_{d}=5$ but not when $T_{d}$ was 7 or 10 .

4.3. CHIL Tests. The long-term CHIL tests were conducted with $T_{d}=7$. Now, the coefficient $T_{c}$ is dependent on the processor capacity of the hardware used. The hardware used for the CHIL tests is an FPGA that has a Dual-Core ARM Cortex $^{\mathrm{TM}}-\mathrm{A} 9(925 \mathrm{MHz})$ processor, as well as $10 / 100 /$ $1000 \mathrm{Mbps}$ Ethernet with a high-speed bus, to exchange data between the hard processor system (HPS) and the FPGA.

This scenario aims to compare the CHIL test results with the real-time SIL test results. The RPW controller is set up to the TSO limits of $\pm 50 \mathrm{kVAr}$, except $\mathrm{QD}_{1}=Q_{i}+200 \mathrm{kVAr}$. Figure 16 presents the results from the tests with the FPGA against the real-time SIL test results when $T_{d}=7$. It can be observed that the results are equal now. 


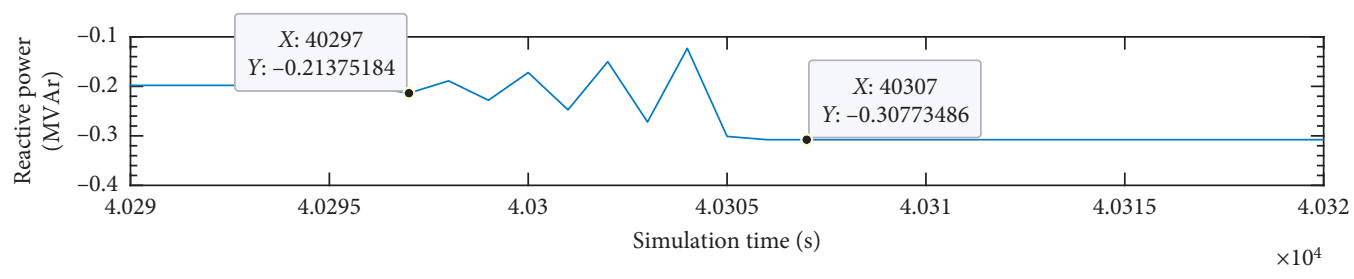

(a)

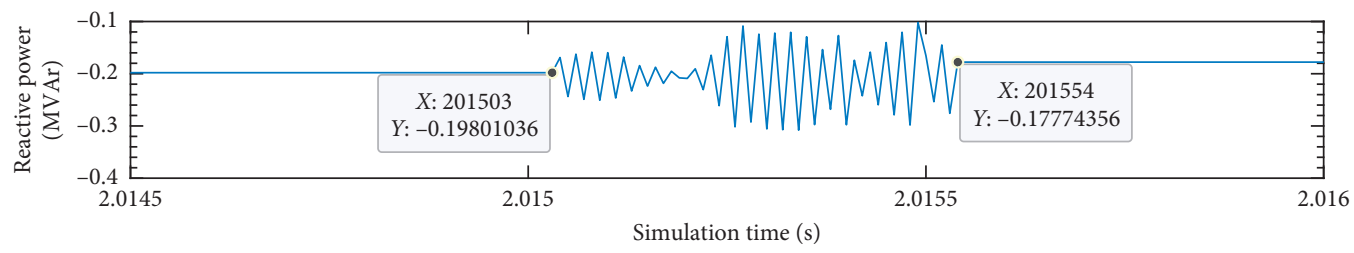

(b)

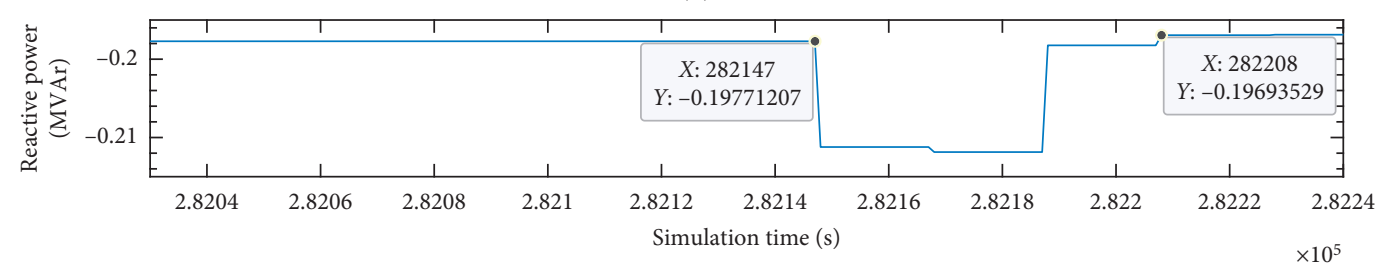

(c)

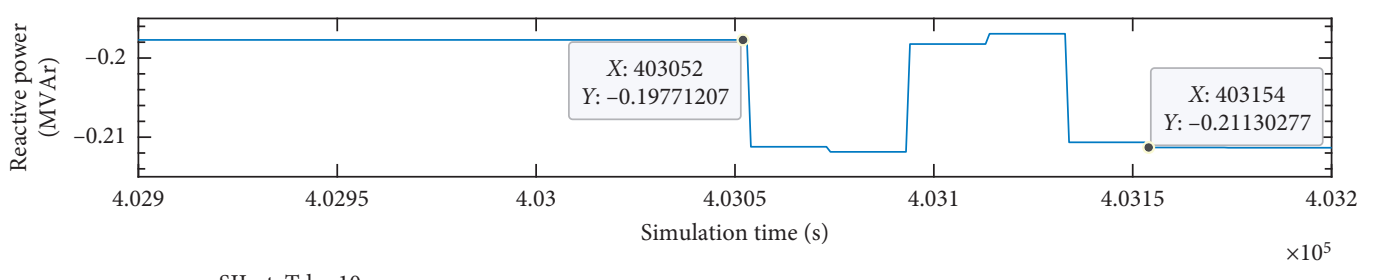

(d)

Figure 15: Results from the real-time SIL real-time test. Reactive power flow at the WT converter between $4029 \mathrm{~h}$ and $4031 \mathrm{~h}$ when $T_{d}=1,5$, 7 , and 10 .

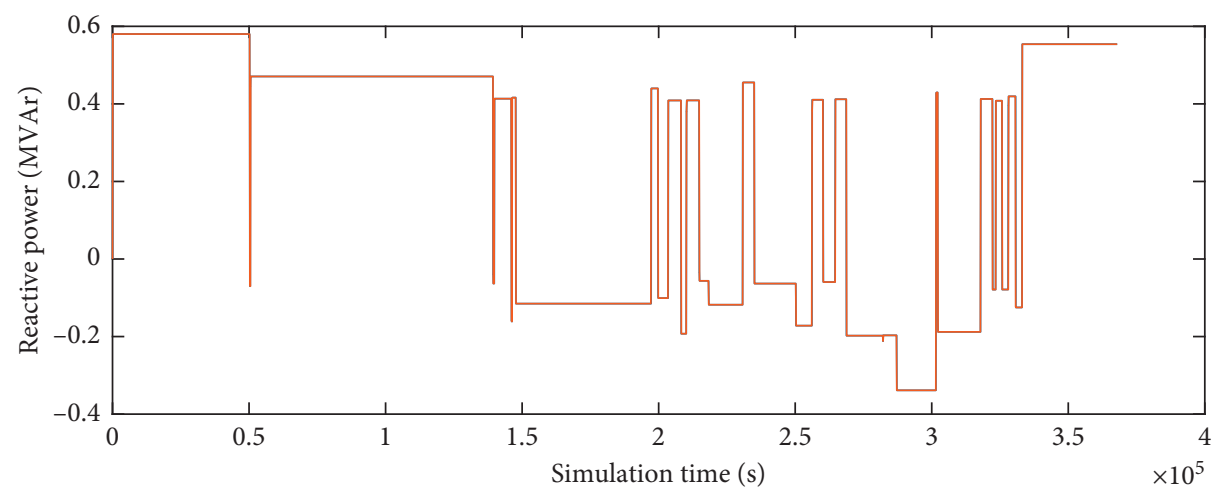

CHIL, $\mathrm{Td}=7$

- SIL rt, Td $=7$

FIGURE 16: Real-time SIL simulation and CHIL results. Reactive power flow of the WT converter when $T_{d}=7$. The RPW controller was set up to the TSO limits of $\pm 50 \mathrm{kVAr}$, except $\mathrm{QD}_{1}=\mathrm{Q}_{i}+200 \mathrm{kVAr}$. 


\section{Conclusions and Discussion}

The accelerated real-time cosimulation platform proves to be useful and efficient in one-year power flow simulations. This research demonstrates how to accelerate the long-term simulations by different setups of the input data. Moreover, this paper clarifies how the input data processed in the longterm simulations or tests affect the results.

The offline SIL and real-time SIL simulations show that it is possible to find a data-reading cycle, coefficient $T_{d}$, to accelerate the long-term real-time simulations. When $T_{d}$ is equal or greater than a particular value, the simulation results do not differ even when $T_{d}$ is increased. Consequently, this value would be a suitable initial value for investigating the coefficient of the accelerated real-time simulations. In addition, it is found that, by increasing the value of $T_{d}$, the possible oscillation period becomes shorter. Further, based on this result, a suitable I or PI controller can be derived for accelerated real-time tests that enable adaptive closed-loop control, preventing oscillations in the closed-loop controlled system. Finally, even in CHIL tests with an FPGA and the selected coefficient $T_{d}$, the results of the real-time SIL and CHIL tests do not differ. The performance of the FPGA shows that it is suitable hardware for testing the algorithm in long-term simulations.

Our suggestion for long-term simulation runs is to carry out offline SIL simulations by using real-time simulation models with different time factors and verify that the results are equal. The time factor for the real-time SIL simulations can then be selected, and the results would be expected to be close to the offline results, with only an effect of the communication time delay. This method could be utilized to define the test procedure, for example, for CHIL applications in the development of microgrid controllers, especially for ancillary services.

The more detailed stability analysis of the proposed control method and detailed technical analysis of the proposed approach will be done in future studies. This paper's aim is to present the potential and the related issues of the developed method for accelerated real-time simulations.

\section{Data Availability}

The data that support the findings of this study are available from the corresponding author upon reasonable request and with permission of Vaasan Sähköverkko.

\section{Conflicts of Interest}

The authors declare that there are no conflicts of interest regarding the publication of this paper.

\section{Acknowledgments}

The research was performed using the ERIGrid Research Infrastructure and received funding from the European Union's Horizon 2020 research and innovation programme under Grant Agreement no. 654113. The support of the European Research Infrastructure ERIGrid and its partner OFFIS e.V. is very much appreciated.

\section{References}

[1] IEEE, Standard for the Specification of Microgrid Controllers, IEEE, Piscataway, NJ, USA, 2017.

[2] IEEE, Standard for the Testing of Microgrid Controllers, IEEE, Piscataway, NJ, USA, 2018.

[3] IEEE, P1547-2018, Interconnection and Interoperability Of Distributed Energy Resources with Associated Electric Power Systems Interfaces, IEEE, Piscataway, NJ, USA, 2018.

[4] IEEE, IEC/TS 62898-1 Microgrids-Part 1: Guidelines for Microgrid Projects Planning and Specification, IEEE, Piscataway, NJ, USA, 2017.

[5] IEEE, IEC, IEC/TS 62898-2 Microgrids-Part 2: Guidelines for Operation (and Control), IEEE, Piscataway, NJ, USA, 2018.

[6] IEEE, IEEE 2030.9-2019-IEEE Approved Draft Recommended Practice for the Planning and Design of the Microgrid, IEEE, Piscataway, NJ, USA, 2019.

[7] IEEE, P2030.10-Standard for DC Microgrids for Rural and Remote Electricity Access Applications, IEEE, Piscataway, NJ, USA, 2019, https://standards.ieee.org/project/2030_10.html.

[8] IEEE, IEC, IEC T. S. 62898-3-1 ED1, Microgrids-Part 3-1: Technical Requirements-Protection and Dynamic Control, IEEE, Piscataway, NJ, USA, 2019, https://www.iec.ch/dyn/ $w w w / f ? p=103: 38: 0$.

[9] IEEE, IEC, IEC T. S. 62898-3-2 ED1, Microgrids-Part 3-2: Technical Requirements-Energy Management Systems, IEEE, Piscataway, NJ, USA, 2019, https://www.iec.ch/dyn/www/f? $\mathrm{p}=103: 38: 15166752842668$.

[10] IEEE, IEC, IEC T. S. 62898-62903-3 ED1,Microgrids-Part 33: Technical requirements-Self-regulation of dispatchable loads, IEEE, Piscataway, NJ, USA, 2019, https://www.iec.ch/ $\mathrm{dyn} / w w w / f ? p=103: 38: 15166752842668$.

[11] S. Sen and V. Kumar, "Microgrid control: a comprehensive survey," Annual Reviews in Control, vol. 45, pp. 118-151, 2018.

[12] M. F. Zia, E. Elbouchikhi, and M. Benbouzid, "Microgrids energy management systems: a critical review on methods, solutions, and prospects," Applied Energy, vol. 222, pp. 1033-1055, 2018.

[13] G. Liu, M. R. Starke, and D. Herron, Microgrid Controller and Advanced Distribution Management Survey Report, Oak Ridge National Laboratory (ORNL), Oak Ridge, TN, USA, 2016.

[14] J. Joos, J. Reilly, W. Bower, and R. Neal, The Need for Standardization: The Benefits to the Core Functions of the Microgrid Control System, IEEE Power and Energy Magazine, Piscataway, NJ, USA, 2017.

[15] J. Reilly, A. Hefner, B. Marchioni, and G. Joos, "Microgrid controller standardization-approach, benefits and implementation," in Proceedings of the CIGRE Grid Of the Future Symposium, Cleveland, WA, USA, October 2017.

[16] A. Maitra, "Microgrid controllers: expanding their role and evaluating their performance," in Proceedings of the IEEE Power and Energy Magazine, pp. 41-49, London, UK, July 2017.

[17] R. Salcedo, E. Corbett, C. Smith et al., "Banshee distribution network benchmark and prototyping platform for hardware-in-the-loop integration of microgrid and device controllers," The Journal of Engineering, vol. 2019, no. 8, pp. 5365-5373, 2019.

[18] E. de Jong, R. de Graaff, P. Vaessen et al., European White Book on Real-Time Power-Hardware-In-The-Loop Testing, European Distributed Energy Resources Laboratories, Et Arnhem, Arnhem, Netherlands, 2011.

[19] K. Sirviö, M. Mekkanen, F. Castro et al., "Testing an IEC 61850-based light-weighted controller for reactive power 
management in smart distribution grids," in Proceedings of the IECON 2019 Conference of the IEEE Industrial Electronics Society (IES), Lisbon, Portugal, October 2019.

[20] W. Ren, M. Steurer, and T. L. Baldwin, "Improve the stability and the accuracy of power hardware-in-the-loop simulation by selecting appropriate interface algorithms," IEEE Transactions on Industry Applications, vol. 44, no. 4, pp. 1286-1294, 2008.

[21] C. Sun, J. N. Paquin, F. Al Jajeh, G. Joos, and F. Bouffard, "Implementation and CHIL testing of a microgrid control system," in Proceedings of the IEEE Energy Conversion Congress and Exposition (ECCE), Portland, WA, USA, October 2018.

[22] R. S. Mongrain, Z. Yu, and R. Ayyanar, "A real-time simulation testbed for hierarchical control of a renewable energybased microgrid," in Proceedings of the IEEE Texas Power and Energy Conference (TPEC), College Station, TX, USA, February 2019.

[23] A. Singh and K. Prabakar, "controller-hardware-in-the-loop testbed for fast-switching SiC-based 50-kW PV inverter," in Proceedings of the IEEE IECON 2018-44th Annual Conference of the IEEE Industrial Electronics Society, Washington, DC, USA, October 2018.

[24] Y. Shan, J. Hu, and J. M. Guerrero, "A model predictive power control method for PV and energy storage systems with voltage support capability," in Proceedings of the IEEE Transactions on Smart Grid, Ontario, Canada, October 2019.

[25] S. Oyegoke, Y. Habtay, M. Maniatopoulos, P. Kotsampopoulos, and S. Keates, "Power hardware in the loop and ancillary service for voltage regulation in low voltage grid," in Proceedings of the 54th International Universities Power Engineering Conference (UPEC), Bucharest, Romania, September 2019.

[26] S. Uebermasser, C. Groiss, A. Einfalt et al., "Requirements for coordinated ancillary services covering different voltage levels," in Proceedings of the CIRED Conference on Electricity Distribution, Glasgow, Scotland, June 2017.

[27] European Commission, Sundom Smart Grid (SSG), EU Project Description, European Commission, Brussels, Belgium, 2019, https://ses.jrc.ec.europa.eu/sundom-smart-grid-ssg.

[28] K. Sirviö, H. Laaaksonen, and K. Kauhaniemi, Active Network Management Scheme for Reactive Power Control, Cired Workshop, Berlin, Germany, 2018.

[29] Commission Regulation (EU), Network Code on Demand Connection, Commission Regulation (EU) 2016/1388, Brussels, Belgium, 2016.

[30] Commission Regulation (EU), Network Code on Requirements for Grid Connected Generators, Commission Regulation (EU), Brussels, Belgium, 2016.

[31] Fingrid, Supply of Reactive Power and Maintenance of Reactive Power Reserves, Fingrid, Helsinki, Finland, 2017, https://www. fingrid.fi/globalassets/dokumentit/en/customers/gridconnection/supply-of-reactive-power-and-maintenance-ofreactive-power-reserves_2017.pdf.

[32] H. Laaksonen and P. Hovila, Flexzone Concept to Enable Resilient Distribution Grids-Possibilities in Sundom Smart Grid, Cired Workshop, Berlin, Germany, 2016.

[33] H. Laaksonen, K. Sirviö, S. Aflecht, and P. Hovila, Multiobjective Active Network Management Scheme Studied in Sundom Smart Grid with MV and LV Network Connected DER Units, Cired Workshop, Berlin, Germany, 2019.

[34] H. Laaksonen, P. Hovila, and K. Kauhaniemi, "Combined islanding detection scheme utilizing active network management for future resilient distributione networks," in
Proceedings of the 14th International Conference on Developments in Power System Protection (DPSP), Liverpool, UK, March 2018.

[35] K. Sirviö, L. Välkkilä, H. Laaksonen, K. Kauhaniemi, and A. Rajala, Prospects and Costs for Reactive Power Control in Sundom Smart Grid, IEEE ISGT Europe, Sarajevo, Bosnia, 2018.

[36] K. Sirviö, M. Mekkanen, F. Castro et al., "Controller development for reactive power flow management between DSO and TSO networks," in Proceedings of the IEEE PES Innovative Smart Grid Technologies Europe (ISGT-Europe), Sarajevo, Bosnia, October 2019. 